\title{
Endovascular stents for treatment of coarctation of the aorta
}

\author{
Aort koarktasyonu tedavisinde endovasküler stentler
}

\author{
Işıl Yıldırım, Tevfik Karagöz, Murat Şahin, Dursun Alehan, Sema Özer, Süheyla Özkutlu, Alpay Çeliker1 \\ Department of Pediatrics Cardiology, Faculty of Medicine, Hacettepe University, Sthhiye, Ankara \\ ${ }^{1}$ Department of Pediatrics, Acıbadem Maslak Hospital, İstanbul-Turkey
}

Coarctation of the aorta $(\mathrm{CoA})$ can be defined as a variable degree of narrowing of the aorta, resulting in pathologic obstruction of blood flow from the systemic ventricle to the systemic circulation. Treatment options include surgical and transcatheter interventions. Endovascular stent implantation has become an important treatment modality of native and recurrent CoA over the past two decades (1-3). We report our experience in implantation of endovascular stents in native and recurrent coarctation of the aorta.

A retrospective analysis of the data of all patients who underwent stent implantation for $\mathrm{CoA}$ between 1999 and 2010 was performed. Patient's demographic and procedural information were obtained and recorded. Follow-up echocardiographic evaluations, aortic arch imaging by cardiac catheterization or computerized tomography (CT) scan and reinterventions were noted.

Between November 1999 and April 2010, 34 patients with $\mathrm{CoA}$ underwent endovascular stent implantation at our institution. Mean age and weight of the patients were $12 \pm 4.6$ years (5-27 y) and $40.2 \pm 17.8 \mathrm{~kg}$ (17-106) respectively (Table 1). Thirtythree of the patients had successful implantation. Of the stents used, 19 were bare while 15 were covered. The one failure was related to stent migration.

The mean minimal CoA diameter and length were $6.4 \pm 2.4 \mathrm{~mm}$ $(1.9-12.1 \mathrm{~mm})$ and $27.2 \pm 5.9 \mathrm{~mm}(12-37 \mathrm{~mm})$, the mean stent length and balloon diameter were $30.1 \pm 4.3 \mathrm{~mm}(22-39 \mathrm{~mm})$ and $14 \pm 2.2$ $\mathrm{mm}$ (10-18 mm) respectively. Mean percent change in CoA diameter post-stent implant was $213 \pm 89 \%(120-452 \%)$. Mean balloon/ CoA ratio was $2.5 \pm 1.1(1.2-6.4)$. The decrease in mean peak-to peak systolic gradient from 37.5 to $7.2 \mathrm{mmHg}$ was statistically significant ( $p<0.001$, Wilcoxon signed ranks test) Mean narrow- est diameter at coarctation site increased in all patients from 6.4 to $11.4 \mathrm{~mm}$, which was statistically significant $(p<0.001$, Wilcoxon signed ranks test).

After discharge, all patients were followed-up in the outpatient clinic for a mean period of 25.7 \pm 30.5 months (1-123 months). Mean gradient assessed by Doppler echocardiography at last follow-up visit was $23.1 \pm 8.8 \mathrm{mmHg}(0-40 \mathrm{mmHg})$. Fourteen patients had an axial CT and seven patients underwent a second catheterization during follow-up. Four patients had stent restenosis and required elective redilation. One patient had a second stent implanted during the second catheterization.

Complications occurred in four patients. In one patient, the initially deployed stent migrated distally; stent was captured by a semi inflated balloon and pulled back as far as the lower thoracic aorta, where it was expanded. Clinically insignificant stent fracture occurred in one patient after stent redilation. Two patients required surgery during long term follow-up, one for formation of femoral arterio-venous fistula and one for total occlusion of the iliac artery.

Without treatment, CoA results in serious morbidity and mortality; with mean life expectancy of 34 years (4). Stent implantation has emerged as an attractive alternative to surgery in recent years. Stents provide excellent radial support across the coarctated segment preventing restenosis and also provide tamponade against the aortic wall, which is especially the case with the covered stents. This tamponade provides both prevention and treatment for intimal tears, aneurysm formation and localized dissections at the site of coarctation (3, 5-8). Similar with other reports, our patients had immediate relief of coarctation, with residual gradient decreasing from $37.5 \mathrm{mmHg}$ to $7.2 \mathrm{mmHg}$.

Address for Correspondence/Yazışma Adresi: Dr. Tevfik Karagöz, Section of Pediatric Cardiology, Department of Pediatrics, Faculty of Medicine, Hacettepe University, Sıhhiye, 06100, Ankara-Turkey Phone: +90 3123051157 Fax: +90 3123090220 E-mail: tkaragoz@hacettepe.edu.tr Accepted Date/Kabul Tarihi: 01.02.2011 Available Online Date/Çevrimiçi Yayın Tarihi: 18.05 .2011 
Table 1. Patient and procedure characteristics $(n=34)$

\begin{tabular}{|l|c|}
\hline Gender, F/M, $\mathrm{n}$ & $13 / 21$ \\
\hline Mean age, years & $12.0 \pm 4.6(5-27)$ \\
\hline Mean weight, $\mathrm{kg}$ & $40.2 \pm 17.8(17-106)$ \\
\hline Previous interventions, $\mathrm{n}(\%)$ & $14(41.2)$ \\
\hline Minimal CoA diameter, $\mathrm{mm}$ & $6.6 \pm 2.6(1.9-12.1)$ \\
\hline CoA length, mm & $27.2 \pm 5.9(12-37)$ \\
\hline Mean stent length, mm & $30.1 \pm 4.3(22-39)$ \\
\hline Mean balloon diameter, mm & $14 \pm 2.2(10-18)$ \\
\hline Mean percent change in CoA diameter, $\%$ & $210 \pm 92(98-452)$ \\
\hline Mean balloon/CoA ratio & $2.5 \pm 1.6(1.2-6.4)$ \\
\hline $\begin{array}{l}\text { Mean peak systolic gradient before and } \\
\text { after stent, mmHg }\end{array}$ & $37.5 \pm 19.1$ \\
\hline Mean poststent CoA diameter, mm & $116-95) / 7.2 \pm 6.6(0-25)$ \\
\hline $\begin{array}{l}\text { Data are presented as number/percentage and mean } \pm S D \\
\text { CoA - coarctation of aorta, } \mathrm{F} \text { - female, M- male }\end{array}$ \\
\hline
\end{tabular}

Complications related with stent implantation can be divided into three categories $(6,8)$ :

1. aortic wall complications (intimal tears, aortic wall dissection/rupture, aortic aneursysm), 2. technical complications (stent migration, balloon rupture), 3. vascular complications (cerebrovascular accident, peripheral embolic event, injury to access vessels, hematoma, bleeding, fistula formation). During mean follow-up time of 25.7 months we have not encountered any complications related to the aortic wall. Integrated imaging of the aortic arch for late occurrence of aortic wall complications is necessary in all patients. Computerized tomography and conventional angiography were performed in 21 of our patients, none of them had aneurysm formation, and only four of them had restenosis. Restenosis is a known complication that may develop because of somatic growth of the patients, intimal hyperplasia, stent recoil or stent fracture. Intimal hyperplasia is thought to be the most common cause $(9,10)$. Stent redilation was performed in these four patients. Apart from the clinically insignificant stent fracture, no major complication was observed with redilation in concordance with previous reports (9).

One patient had stent migration during implantation. The coarctation in this patient was situated at the curvature of the transverse aorta, and it was not possible to stabilize the stent and the long sheath during inflation. Retrospectively thinking, perhaps rapid ventricular pacing could have prevented forward flow of blood and could have stabilized the long sheath and the stent. Two patients had injury of the access vessel; one was formation of an arterio-venous fistula, which is probably related to the access site and technique for initial puncture, probably not related to the procedure. The other complication, however, was total occlusion of the iliac artery, which happened in smallest of our patients. The major disadvantage of stent implantation is requirement of a long sheath large enough to accommodate the stent and the balloon. Use of large sheaths limits the availability of this technique to small children.

\section{Conclusion}

Endovascular stenting for the treatment of native and recurrent coarctation of the aorta appears to be a feasible, safe and efficient method. Some patients may require further stent enlargement during follow-up. Patients should be followed-up closely for recoarctation and development of hypertension. Integrated aortic arch imaging to assess neointimal proliferation and formation of aneurysm is crucial.

Conflict of interest: None declared.

\section{References}

1. Hamdan MA, Maheshwari S, Fahey JT, Hellenbrand WE. Endovascular stents for coarctation of the aorta: initial results and intermediate-term follow-up. J Am Coll Cardiol 2001; 38: 1518-23.

2. Baykan A, Karagöz T, Çeliker A. Endovascular stent implantation for coarctation of the aorta in children and young adults: intermediate follow-up results from Turkey. Turk J Pediatr 2009; 51 : 116-9.

3. Suarez de lezo J, Pan M, Romero M, Sequra J, Pavlovic D, Ojeda S, et al. Percutaneous Interventions on severe coarctation of the aorta: a 21-year experience. Pediatr Cardiol 2005; 26: 176-89.

4. Golden $A B$, Hellenbrand WE. Coarctation of the aorta: stenting in children and adults. Catheter Cardiovasc Interv 2007; 69: 289-99.

5. Tzifa A, Ewert P, Brzezinska-Rajszys G, Peters B, Zubrzycka M, Rosenthal $E$, et al. Covered Cheatham-platinum stents for aortic coarctation: early and intermediate-term results. J Am Coll Cardiol 2006; 47: 1457-63.

6. Forbes TJ, Garekar S, Amin Z, Zahn EM, Nykanen D, Moore P, et al. Congenital Cardiovascular Interventional Study Consortium (CCISC). Procedural results and acute complications in stenting native and recurrent coarctation of the aorta in patients over 4 years of age: a multi-institutional study. Catheter Cardiovasc Interv 2007; 70: 276-85.

7. Thanopoulos BD, Hadjinikolaou L, Konstadopoulou GN, Tsaousis GS, Triposkiadis F, Spirou P. Stent treatment for coarctation of the aorta: intermediate term follow up and technical considerations. Heart 2000; 84: 65-70.

8. Forbes TJ, Moore P, Pedra CA, Zahn EM, Nykanen D, Amin Z, et al. Intermediate follow-up following intravascular stenting for treatment of coarctation of the aorta. Catheter Cardiovasc Interv 2007; 70: 569-77.

9. Zanjani KS, Sabi T, Moysich A, Ovroutski S, Peters B, Miera O, et al. Feasibility and efficacy of stent redilatation in aortic coarctation. Catheter Cardiovasc Interv 2008; 72: 552-6.

10. Holzer R, Qureshi S, Ghasemi A, Vincent J, Sievert H, Gruenstein D, et al. Stenting of aortic coarctation: acute, intermediate, and longterm results of a prospective multi-institutional registry-Congenital Cardiovascular Interventional Study Consortium (CCISC). Catheter Cardiovasc Interv 2010; 76: 553-63. 